\title{
Community-based assessment of infant feeding practices within a programme for prevention of mother-to-child HIV transmission in rural Zimbabwe
}

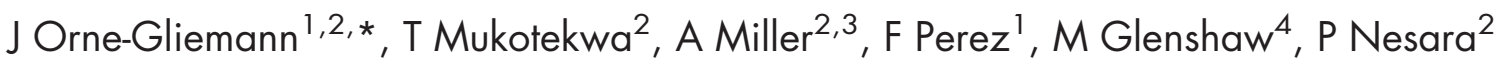 \\ and $\mathrm{F}_{\text {Dabis }}{ }^{1}$ \\ ${ }^{1}$ ISPED, Université Victor Segalen - Bordeaux 2, 146 rue Leo Saignat, F-33076 Bordeaux, France: ${ }^{2}$ ISPED \\ Zimbabwe, 33 Lawson Avenue, Milton Park, Harare, Zimbabwe: ${ }^{3} E G P A F$ Zimbabwe, 33 Lawson Avenue, \\ Milton Park, Harare, Zimbabwe: ${ }^{4}$ Murambinda Mission Hospital, PO Box 20, Murambinda Growth Point, \\ Zimbabwe
}

Submitted 3 May 2005: Accepted 11 October 2005

\begin{abstract}
Objective: To describe the infant feeding practices and attitudes of women who used prevention of mother-to-child transmission of HIV (PMTCT) services in rural Zimbabwe.

Design: A cross-sectional study including structured interviews and focus group discussions was conducted between June 2003 and February 2004.

Setting: The study took place in Murambinda Mission Hospital (Buhera District, Manicaland Province), the first site offering PMTCT services in rural Zimbabwe.

Subjects: The interviews targeted HIV-infected and HIV-negative women who received prenatal HIV counselling and testing and minimal infant feeding counselling, and who delivered between 15 August 2001 and 15 February 2003. The focus groups were conducted among young and elderly men and women. Results: Overall, 71 HIV-infected and 93 HIV-negative mothers were interviewed in clinics or at home. Most infants (97\%) had ever been breast-fed. HIV-negative mothers introduced fluids/foods other than breast milk significantly sooner than HIV-infected mothers (median 4.0 vs. 6.0 months, $P=0.005$ ). Infants born to HIV-negative mothers were weaned significantly later than HIV-exposed infants (median 19.0 vs. 6.0 months, $P=10^{-5}$ ). More than $90 \%$ of mothers reported that breast-feeding their infant was a personal decision, a third of whom also mentioned having taken into account health workers' messages.

Conclusion: The HIV-infected mothers interviewed were gradually implementing infant feeding practices recommended in the context of HIV. Increased infant feeding support capacity in resource-limited rural populations is required, i.e. training of counselling staff, decentralised follow-up and weaning support.
\end{abstract}

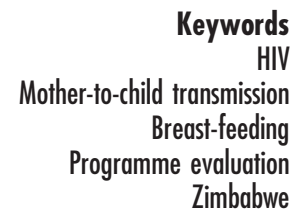

Breast-feeding has been shown to contribute greatly to child health ${ }^{1}$. It is also a critical route of mother-to-child transmission of HIV (MTCT) in the postnatal period, representing a third of the total risk of MTCT among breast-feeding populations ${ }^{2}$. Exclusive breast-feeding has been suggested to carry less risk of postnatal transmission of HIV than mixed feeding ${ }^{3,4}$. Early cessation of exclusive breast-feeding to minimise the cumulative risk of MTCT is advised in very specific conditions, i.e. if replacement feeding is acceptable, feasible, affordable, sustainable and safe. The World Health Organization (WHO) has developed guidelines on infant feeding practices in the context of $\mathrm{HIV}^{5}$ and regularly revises messages to be provided according to the best available evidence ${ }^{6}$. The uptake of the recommended WHO infant feeding strategies has not been extensively investigated so far in the context of operational programmes for the prevention of mother-tochild transmission of HIV (PMTCT) in rural Africa ${ }^{7}$.

In Zimbabwe, the national HIV prevalence among adults aged $15-49$ years was estimated at $24.6 \%$ in $2003^{8}$. The Ministry of Health and Child Welfare $(\mathrm{MOH} / \mathrm{CW})$ developed its first HIV/AIDS policy in 1999 and launched pilot PMTCT activities in selected urban areas in the same year. The national infant feeding policy as well as nursing training curricula have been adapted accordingly, to ensure that appropriate educational messages are provided to women of childbearing age ${ }^{9,10}$. Murambinda Mission Hospital (Buhera District, Manicaland Province) was the first pilot site to introduce PMTCT services in a rural setting, in August $2001^{11}$. 
At Murambinda Mission Hospital, which is certified in the Baby-Friendly Hospital Initiative ${ }^{12}$, all mothers are encouraged to breast-feed. In 2001, in addition to the three PTMCT counsellors operating at that time, hospital staff members were trained in infant feeding and HIV using a locally developed curriculum based on the $2000 \mathrm{WHO} /$ UNICEF/UNAIDS course ${ }^{13}$. Since then, exclusive breastfeeding until 6 months has been recommended for all mothers, followed by - when feasible and safe for HIVinfected women - early and rapid weaning 5 . Infant feeding education is given to all women during antenatal care clinic visits, during pre- and post-test HIV counselling sessions and in subsequent postnatal visits. HIV-specific infant feeding counselling is provided to HIV-infected mothers only, before and after delivery and during any further postnatal visit, when requested by women. No outreach counselling in the Buhera community or home visits are undertaken. Furthermore, no nutritional support was provided, in agreement with national guidelines at that time.

Exclusive breast-feeding is not common in most areas of Zimbabwe: in 1999, based on the 24-hour recall method, it was estimated to be practised by 39 and $8 \%$ of mothers until 4 and 6 months, respectively ${ }^{14}$. Women may experience problems explaining alternative infant feeding practices to their families, especially in the context of HIV infection ${ }^{15}$. The present study aimed at estimating the uptake of recommended infant feeding practices within a poor rural district of Zimbabwe. Its objectives were to describe the reported infant feeding practices of women who received the Murambinda PMTCT services and to document the socio-cultural context in which infant feeding decisions are made.

\section{Method}

We used two research strategies: a cross-sectional community-based survey and focus group discussions (FGDs). We report here primarily on the quantitative survey results. The qualitative data collected during the FGDs provide a complementary description of the sociocultural context in which reported infant feeding practices may be understood.

The survey targeted mothers who were tested for HIV in Murambinda and delivered between 15 August 2001 and 15 February 2003. A total of 274 women were identified from the PMTCT programme's monitoring records. Eligible HIV-infected mothers were all those who reported nevirapine intake (mother and/or infant dose) and agreed to a two-year follow-up $(n=129)$. HIV-negative women were randomly selected from the monitoring records; using the Epi-Info ${ }^{\circledR}$ calculator, the sample size $(n=145)$ was chosen on the basis of an expected $15 \%$ prevalence of exclusive breast-feeding at 6 months among HIV-negative women (comparable to national statistics) to be estimated with an alpha type I error of 5\%.

Four trained interviewers performed clinic-based and home-based interviews between June 2003 and February 2004. Follow-up of women known to have moved from their initial address was restricted to the bordering districts. A woman was considered lost to follow-up after three contact attempts and no replacement procedure was used. No maternal interview was performed if the infant was deceased. The infant's primary caregiver was interviewed if the mother had died. In the case of multiple births, the first-born child only was included to document infant feeding practices.

The survey tool was a structured questionnaire adapted from $\mathrm{WHO}^{16,17}$. The first section described the sociodemographic characteristics of the mother and caregiver interviewed (19 closed-ended questions). The second section collected data on infant feeding practices, self-reported by the mother or caregiver ( 74 closedended questions). It described the breast-feeding duration, the weaning process and the complementary feeding patterns using the 'ever', 24-hour and 7-day recall methods; it addressed the decision process for breast-feeding and weaning (decision-makers, influential factors); and it also assessed the use of infant feeding counselling services and other forms of support. Each interview lasted approximately $45 \mathrm{~min}$.

A total of seven FGDs, comprising 12 participating members each, were held in the district, targeting specific groups within the community: young and elderly males, traditional healers, traditional midwives and elderly women. The discussion guide (37 questions) was adapted from the questionnaire with the caregivers. All the answers were handwritten during the discussions and transcribed later.

Statistical analysis of the data was performed using SPSS $^{\mathrm{TM}}$ version 10.0 for Windows (SPSS Inc., Chicago, IL, USA), Access 2000 (Microsoft $^{\circledR}$ Corp., Redmond, WA, USA), Epi-Info ${ }^{\mathrm{TM}}$ (Centers for Disease Control and Prevention, Atlanta, GA, USA) and Stata ${ }^{\mathrm{TM}} 8.0$ (Stata Corp., College Station, TX, USA). To highlight significant statistical differences according to the sero-status of the targeted mothers, statistical comparisons used Student's $t$ test or the Mann-Whitney test for quantitative continuous data and Fisher's exact test or the chi-square test for categorical data.

\section{Results}

The survey response rate was $60 \%$ of the mothers targeted (164/274) and was not statistically different between the two groups: $55.0 \%$ of the 129 HIV-infected women versus $64.1 \%$ of the $145 \mathrm{HIV}$-negative women $(P=0.08)$. The main reasons for women not being interviewed were the traditional practice of delivery in the parental village (and therefore primary residence outside Buhera District) 
(25.5\% overall) and the inability to identify women at village level because erroneous addresses or names were provided at pre-test counselling (30.9\%). Deaths, recorded during the fieldwork and on the interview forms, were as follows: nine infant and maternal deaths, 11 infant deaths (mother still alive) and eight maternal deaths (infant still alive, thus the interview was performed). The cause and date of death were not documented (Table 1).

\section{Sociodemographic characteristics}

Out of the 164 interviews completed, 156 (95\%) were conducted with the mothers themselves and eight with other primary caregivers. The sociodemographic profile of the women interviewed did not differ according to sero-status. The large majority of women were unemployed and belonging to the Apostolic church (who do not believe in modern medicine). Most women (45\%) were aged between 25 and 34 years. A significantly higher proportion of HIV-infected women were widowed (14.1 vs. $3.2 \%, P=0.01)$. More than a third of women were primiparous (Table 2). The age of infants at the time of interview ranged from 4 to 29 months, with two-thirds of infants aged between 7 and 18 months.

\section{Infant feeding practices}

Infant feeding practices are summarised in Table 3.

\section{Breast-feeding}

The vast majority of infants included in the cross-sectional survey had ever been breast-fed ( $n=159,97 \%)$. The five infants who were never breast-fed were born to HIV-infected mothers. Among the mothers still breastfeeding at the time of interview $(n=105)$, HIV-negative women $(n=70)$ reported their intention to breast-feed their infant for a significantly longer period than the 35
HIV-infected women (22 months on average vs. 17 months, $P=0.0001)$.

All seven FGDs stated that, in the Buhera community, the average duration of breast-feeding was 24 months.

\section{Complementary feeding}

The FGD comprising young males believed that complementary feeding could start at 4 months, whereas the other six groups stated 6 months as the ideal age. Women interviewed during the survey indicated that infants were given fluids/foods other than breast milk between 1 week and 14 months of age, and significantly sooner among HIV-negative than HIV-infected mothers (median 4.0 vs. 6.0 months, $P<0.01$ ) (Table 4).

Among the infants currently breast-fed and having received foods/fluids other than breast milk at the time of interview ( $n=102$ ), almost all $(95 \%)$ had been given plain water in the seven days before the interview. Among the other main complementary fluids ever given to infants, irrespective of their age, were fruit juice, tea with milk and fresh milk from cows. Infant formula was ever given to six HIV-exposed infants (9.2\%). Sadza, the national staple food consisting of a thick maize porridge (91\%), thin porridge without milk (68-80\%) and mashed vegetables $(67-73 \%)$ were the main complementary foods used.

All FGDs reported that the type of weaning foods was mainly dependent on household supplies, as infant and family meals were prepared together (e.g. for sadza, only the cooking duration and therefore the thickness of the dish differs).

\section{Weaning}

Half of infants born to HIV-infected mothers and weaned at the time of the interview had been weaned at 6 months (56\%) whereas this was never reported among infants born to HIV-negative mothers. Infants born to

Table 1 Completion of interviews according to HIV status of the women, Buhera District, Zimbabwe, 2003-2004

\begin{tabular}{|c|c|c|c|c|c|c|c|}
\hline & \multicolumn{2}{|c|}{$\begin{array}{l}\text { HIV-infected } \\
\quad(N=129)\end{array}$} & \multicolumn{2}{|c|}{$\begin{array}{l}\text { HIV-negative } \\
\quad(N=145)\end{array}$} & \multicolumn{2}{|c|}{ Total $(N=274)$} & \multirow[b]{2}{*}{$P$-value } \\
\hline & $n$ & $\%$ & $n$ & $\%$ & $n$ & $\%$ & \\
\hline Interview completed & 71 & $55.0(100)$ & 93 & $64.1(100)$ & 164 & $59.9(100)$ & $0.08^{*}$ \\
\hline Mother alive & 64 & 90.1 & 92 & 98.9 & 156 & 95.1 & $0.02 \dagger$ \\
\hline Mother deceased & 7 & 9.9 & 1 & 1.1 & 8 & 4.9 & \\
\hline Interview not completed & 58 & $45.0(100)$ & 52 & $35.9(100)$ & 110 & $40.1(100)$ & \\
\hline Infant deceased & 9 & 15.5 & 2 & 3.8 & 11 & 10.0 & $0.01 \ddagger$ \\
\hline Infant and mother deceased & 8 & 13.8 & 1 & 1.9 & 9 & 8.2 & \\
\hline Not identified as living in the village & 18 & 31.0 & 16 & 30.8 & 34 & 30.9 & \\
\hline $\begin{array}{l}\text { Returned to marital home after delivery } \\
\text { in parental home district }\end{array}$ & 9 & 15.5 & 19 & 36.5 & 28 & 25.5 & \\
\hline $\begin{array}{l}\text { changed address for another reason } \\
\text { (within Buhera or to another district) }\end{array}$ & 6 & 10.3 & 5 & 9.6 & 11 & 10.0 & \\
\hline Other (refused, no response) & 8 & 13.8 & 9 & 17.3 & 17 & 15.5 & \\
\hline
\end{tabular}

* Completion rate by HIV sero-status.

† Maternal death rate by HIV sero-status.

‡Distribution of reasons for not completing the interviews by HIV sero-status. 
Table 2 Selected sociodemographic characteristics of caregivers of infants according to HIV status of the mothers, Buhera District, Zimbabwe, 2003-2004

\begin{tabular}{|c|c|c|c|c|c|}
\hline \multirow[b]{2}{*}{$N=164^{\star}$} & \multicolumn{2}{|c|}{$\begin{array}{c}\text { HIV- } \\
\text { infected } \\
(N=71)\end{array}$} & \multicolumn{2}{|c|}{$\begin{array}{c}\text { HIV-nega- } \\
\text { tive } \\
(N=93)\end{array}$} & \multirow[b]{2}{*}{$P$-value } \\
\hline & $n$ & $\%$ & $n$ & $\%$ & \\
\hline \multicolumn{6}{|l|}{ Age (years) } \\
\hline $15-24$ & 22 & 32.4 & 42 & 46.2 & \\
\hline $25-34$ & 33 & 48.5 & 38 & 41.8 & \\
\hline Above 34 & 13 & 19.1 & 11 & 12.1 & \\
\hline Missing & 3 & 4.2 & 2 & 2.2 & \\
\hline Median & \multirow{2}{*}{\multicolumn{2}{|c|}{$\begin{array}{c}27.8 \\
22.0-33.0\end{array}$}} & \multirow{2}{*}{\multicolumn{2}{|c|}{$\begin{array}{c}24.5 \\
21.0-31.0\end{array}$}} & 0.08 \\
\hline Interquartile range & & & & & \\
\hline \multicolumn{6}{|l|}{ Marital status } \\
\hline Married & 51 & 71.8 & 87 & 93.6 & $<0.01$ \\
\hline Widowed & 10 & 14.1 & 3 & 3.2 & \\
\hline Other & 10 & 14.1 & 3 & 3.2 & \\
\hline \multicolumn{6}{|l|}{ Number of pregnancies } \\
\hline 1 & 20 & 28.6 & 38 & 40.9 & \\
\hline 2 & 9 & 12.9 & 14 & 15.0 & \\
\hline 3 & 13 & 18.6 & 7 & 7.5 & \\
\hline 4 or 5 & 11 & 15.7 & 21 & 22.6 & \\
\hline More than 6 & 17 & 24.3 & 13 & 14.0 & \\
\hline Missing & 1 & 1.4 & 0 & 0 & \\
\hline Median & \multirow{2}{*}{\multicolumn{2}{|c|}{$\begin{array}{c}3.0 \\
1.0-5.25\end{array}$}} & \multirow{2}{*}{\multicolumn{2}{|c|}{$\begin{array}{c}2.0 \\
1.0-5.0\end{array}$}} & 0.13 \\
\hline Interquartile range & & & & & \\
\hline \multicolumn{6}{|l|}{ Education } \\
\hline No formal education & 2 & 2.8 & 0 & 0 & 0.71 \\
\hline Primary school & 21 & 29.6 & 30 & 33.0 & \\
\hline Secondary school & 48 & 67.6 & 59 & 64.8 & \\
\hline Higher education & 0 & 0 & 2 & 2.2 & \\
\hline Missing & 0 & 0 & 2 & 2.1 & \\
\hline \multicolumn{6}{|l|}{ Employment } \\
\hline Formal & 5 & 7.1 & 7 & 7.5 & 0.53 \\
\hline Informal & 3 & 4.3 & 2 & 2.2 & \\
\hline $\begin{array}{l}\text { Unemployed } \\
\text { (housewife) }\end{array}$ & 61 & 87.1 & 83 & 89.3 & \\
\hline Other & 1 & 1.4 & 0 & 0 & \\
\hline Missing & 1 & 1.4 & 0 & 0 & \\
\hline \multicolumn{6}{|l|}{ Religion } \\
\hline Apostolic & 42 & 60.0 & 52 & 55.9 & 0.22 \\
\hline Protestant & 10 & 14.3 & 20 & 21.5 & \\
\hline Roman Catholic & 8 & 11.4 & 4 & 4.3 & \\
\hline Other & 10 & 14.3 & 17 & 18.3 & \\
\hline Missing & 1 & 1.4 & 0 & 0 & \\
\hline \multicolumn{6}{|l|}{ People in the household } \\
\hline 1 to 3 & 22 & 32.4 & 18 & 20.9 & \\
\hline 4 to 6 & 31 & 45.6 & 46 & 53.5 & \\
\hline More than 6 & 15 & 22.1 & 22 & 25.6 & \\
\hline Missing & 3 & 4.2 & 7 & 7.5 & \\
\hline Median & \multicolumn{2}{|c|}{4.0} & \multicolumn{2}{|c|}{5.0} & 0.09 \\
\hline Interquartile range & \multicolumn{2}{|c|}{$3.0-6.0$} & \multicolumn{2}{|c|}{$4.0-7.0$} & \\
\hline
\end{tabular}

${ }^{*}$ In the case of five HIV-exposed infants and three infants born to HIVnegative mothers, these data apply to primary caregivers whose HIV status is unknown.

HIV-negative mothers were weaned significantly later than HIV-exposed infants (median 19.0 vs. 6.0 months, $P<0.01$ ) (Table 4).

Most infants were reported to be weaned within 24 hours. The main weaning strategies used by the HIVinfected mothers were to feed the infant with another fluid/food $(57 \%)$ or to send their infant to a neighbour (41\%). Most HIV-infected mothers reported weaning their infants in response to their concern about HIV transmission (72.7\%) and to health workers' messages (51.5\%). Infants born to HIV-negative mothers were more likely than HIV-exposed infants to be weaned 'because they were old enough' (52.6 vs. 10.7\%, $P=0.0003$ ).

\section{Factors associated with infant feeding practices}

More than $90 \%$ of mothers reported that starting their infant on breast milk was a personal decision and a third mentioned having followed health workers' messages (non-exclusive answers). The importance of breast milk for the infant's health was the main motive for mothers to breast-feed (above 95\% of responses), regardless of their HIV status. Most mothers (57\%) also mentioned that breast-feeding was a cultural expectation. A large proportion of HIV-infected mothers declared having opted for breast-feeding due to financial constraints (60\%).

Most mothers were decision-makers on current infant feeding practices, with the partners of HIV-negative women being more likely to be involved in infant feeding decisions than those of HIV-infected mothers (33.8 vs. $11.5 \%, P<0.01)$. Grandmothers prepared fluids/foods for $45.5 \%$ and $31.2 \%$ of the infants born HIV-negative and HIV-infected mothers, respectively $(P=0.06)$.

All FGDs also underlined that support from the family was essential. The traditional midwives and elderly women interviewed during the FGDs, however, highlighted that young mothers often did not ask for their assistance. Although they felt they could teach mothers appropriate infant feeding practices, they usually did not wish to interfere.

Most mothers (71.3\%) reported having discussed infant feeding practices at some point in time with the hospital health workers or the trained PMTCT counsellors, with no significant difference according to their HIV status. Almost all women declared that these discussions were informative and assisted them in making infant feeding decisions. Few women had received home visits from health workers since delivery, whether to discuss infant feeding or other health issues (11.4 and 17.2\% of HIV-infected and HIVnegative mothers, respectively; $P=0.37$ ).

\section{Discussion}

Undertaking a community-based follow-up of mothers and infants for evaluating the infant feeding component of a PMTCT programme has been complex in this rural Zimbabwean setting. Indeed, despite an active field strategy, with personal invitations to health centres or home interviews, many targeted mothers could not be reached. Notwithstanding the high mortality rate associated with HIV infection, population mobility has been reported to be high in rural Zimbabwe ${ }^{18}$. Furthermore, traditionally, women deliver in their parental district, especially primiparous women. Therefore being several 
Table 3 Estimations of infant feeding practices according to HIV status of the mothers, Buhera District, Zimbabwe, 2003-2004

\begin{tabular}{|c|c|c|c|c|c|c|c|c|c|}
\hline & \multicolumn{3}{|c|}{ HIV-infected } & \multicolumn{3}{|c|}{ HIV-negative } & \multicolumn{3}{|c|}{ Total } \\
\hline & $n$ & $\%$ & $N$ & $n$ & $\%$ & $N$ & $n$ & $\%$ & $N$ \\
\hline Infants included in the study sample & 71 & 55.0 & 129 & 93 & 64.1 & 145 & 164 & 59.9 & 274 \\
\hline Infant ever breast-fed & 66 & 93.0 & 71 & 93 & 100 & 93 & 159 & 97.0 & 164 \\
\hline Infant still breast-feeding at interview & 35 & 53.0 & 66 & 70 & 75.3 & 93 & 105 & 66.0 & 159 \\
\hline Infant having been fed fluids/foods & 70 & 98.6 & 71 & 91 & 97.8 & 93 & 161 & 98.2 & 164 \\
\hline other than breast milk at interview & & & & & & & & & \\
\hline Infant having been weaned at interview & 33 & 54.1 & 61 & 24 & 27.9 & 86 & 57 & 38.8 & 147 \\
\hline
\end{tabular}

months postpartum, they had returned to their husbands' home and were thus untraceable.

The main limitation of this study is its cross-sectional design. The estimations of infant feeding practices were based on self-reported data that were collected during a single interview, and this may have led to recall bias in reporting the age at introduction of fluids/foods other than breast milk, as shown elsewhere ${ }^{19}$. We thus did not report constructed estimations of exclusive breast-feeding and mixed feeding rates. However, our study results provide some insight on the type of infant feeding practices that women - who were aware of their HIV status and had benefited from minimal infant feeding education and support - chose to report to the health staff conducting the survey. Furthermore, the combined use of quantitative and qualitative research methods to document 'real-life' situations of mothers and operational PMTCT initiatives in a rural African area severely affected by HIV is one of the strengths of our study.

The fact that the HIV-infected mothers interviewed were more likely than their HIV-negative counterparts to have delayed the introduction of complementary feeding, and weaned their infant sooner, indicates a gradual, response to HIV-related infant feeding recommendations. There are however certain practical and cultural barriers to the adoption of safe infant feeding practices in the context of HIV infection.

The women interviewed and the FGD members reported that the main motive to breast-feed was the importance of breast milk for the infant's health, confirming that breastfeeding is a universal practice and a social norm in Zimbabwe $^{14}$. Many HIV-infected mothers also declared having opted for breast-feeding due to financial constraints. Similar findings have been reported in Kenya ${ }^{20}$. Buhera is one of the poorest rural districts in Zimbabwe, facing a lack of available clean water and numerous barriers to the preparation of infant formula for HIV-exposed infants. These economic and environmental constraints reported during our study are susceptible to have been exacerbated by the drought that affected this part of Africa in 2002. Our results should thus not necessarily be generalised to other regions and time periods.

Difficulties in purchasing and preparing replacement feeding may partly explain why early cessation of

Table 4 Selected infant feeding indicators according to HIV status of the mothers, Buhera District, Zimbabwe, 2003-2004

\begin{tabular}{|c|c|c|c|c|c|c|c|}
\hline & \multicolumn{2}{|c|}{ HIV-infected } & \multicolumn{2}{|c|}{ HIV-negative } & \multicolumn{2}{|c|}{ Total } & \multirow[b]{2}{*}{$P$-value } \\
\hline & $n$ & $\%$ & $n$ & $\%$ & $n$ & $\%$ & \\
\hline Age at introduction of fluids/foods & \multirow{2}{*}{\multicolumn{2}{|c|}{$N=66$}} & \multirow{2}{*}{\multicolumn{2}{|c|}{$N=93$}} & \multicolumn{2}{|c|}{$N=159$} & \\
\hline other than breast milk (months) ${ }^{*}$ & & & & & & & \\
\hline Under 1 & 1 & 1.6 & 4 & 4.4 & 5 & 3.2 & \\
\hline $1-4$ & 13 & 20.3 & 40 & 44.0 & 53 & 34.2 & \\
\hline 5 & 2 & 3.1 & 11 & 12.1 & 13 & 8.4 & \\
\hline 6 & 36 & 56.2 & 20 & 22.0 & 56 & 36.1 & \\
\hline 7 and above & 12 & 18.8 & 16 & 17.6 & 28 & 18.1 & \\
\hline Missing & 2 & 3.0 & 2 & 2.1 & 4 & 2.5 & \\
\hline Mean (95\% confidence interval) & \multirow{2}{*}{\multicolumn{2}{|c|}{$\begin{array}{l}5.7(5.2-6.2) \\
6.0(5.0-6.0)\end{array}$}} & \multirow{2}{*}{\multicolumn{2}{|c|}{$\begin{array}{l}4.9(4.4-5.5) \\
4.0(4.0-6.0)\end{array}$}} & \multirow{2}{*}{\multicolumn{2}{|c|}{$\begin{array}{l}5.2(4.9-5.6) \\
6.0(4.0-6.0)\end{array}$}} & 0.04 \\
\hline Median (interquartile range) & & & & & & & $<0.01$ \\
\hline Age at weaning (months) $\dagger$ & \multicolumn{2}{|c|}{$N=32$} & \multicolumn{2}{|c|}{$N=24$} & \multicolumn{2}{|c|}{$N=56$} & \\
\hline 6 & 18 & 56.0 & 0 & 0 & 18 & 32.0 & \\
\hline $7-12$ & 7 & 22.0 & 2 & 8.7 & 9 & 16.0 & \\
\hline $13-18$ & 7 & 22.0 & 7 & 30.4 & 14 & 25.0 & \\
\hline Above 18 & 0 & 0 & 14 & 60.9 & 14 & 25.0 & \\
\hline Missing & & 0 & & 4.2 & & 1.8 & \\
\hline Mean (95\% confidence interval) & \multicolumn{2}{|c|}{$9.2(7.6-10.4)$} & \multicolumn{2}{|c|}{$18.6(17.8-20.4)$} & \multicolumn{2}{|c|}{$13.0(11.3-14.7)$} & $<0.05$ \\
\hline Median (interquartile range) & \multicolumn{2}{|c|}{$6.0(6.0-11.25)$} & \multicolumn{2}{|c|}{$19.0(17.0-21.0)$} & \multicolumn{2}{|c|}{$12.0(6.0-19.0)$} & $<0.05$ \\
\hline
\end{tabular}

* Among infants reported to have been ever breast-fed.

†Among infants reported to have been ever breast-fed and weaned at the time of interview. 
breast-feeding was infrequently practised among the HIVinfected mothers interviewed. Women neither owned cows for animal milk nor had sufficient financial resources to purchase commercial milk, and thus made the best choice by maintaining breast-feeding to ensure adequate nutritional intake for their infant. Cessation of breast-feeding at 6 months may not be appropriate and safe in such poor settings. This constrained socioeconomic context may also explain why we did not observe any 'spill-over effect' with regard to early cessation of breast-feeding in this rural population, i.e. the recommendations provided during prenatal care for HIV-infected mothers do not seem to have affected the weaning age of HIV-negative mothers.

Furthermore, breast-feeding until 18 months is the norm in Zimbabwe and women may be faced with a cultural dilemma when wishing to take their baby off the breast early. The rapid adoption of new practices recommended internationally is indeed often constrained by their inability to be integrated within health and community systems. The Zimbabwe child health card, recommending breast-feeding until 18 months, is currently being revised to include updated infant feeding messages in the context of HIV/AIDS. It will be interesting to evaluate the feasibility and impact of these new infant feeding messages.

Our study showed that infants were often fed with adult foods as complementary or weaning foods. Education and promotion of appropriate replacement foods to accompany early cessation of breast-feeding have been insufficient so far in Zimbabwe. Any innovative recommendations for replacement feeding, in contexts where food availability and household financial capacity are scarce, will require strengthened support to mothers and families.

Most mothers reported making their own decisions regarding infant feeding. Partners were rarely mentioned as decision-makers on infant feeding practices, whether by the mothers interviewed or the focus group members. Local antenatal services do not accommodate men and, in this rural African setting, the tradition is that men do not look after babies. The high proportion of maternal decision-making regarding infant feeding may also be related to the absence of disclosure of women's HIV status to their partner and family ${ }^{21}$, although our study did not document the disclosure patterns after antenatal HIV testing. Involvement and support from family members could further encourage mothers to implement safe infant feeding practices for PMTCT, practices that are different from cultural norms and conventional public health messages. However, the direct impact of socio-cultural constraints within the community, such as stigmatisation or discrimination, on infant feeding practices is yet to be documented.

Our study results show a discrepancy between mothers' appreciation of education and support services and their accessibility within the community. Supervision and continuous training of staff are needed to ensure that appropriate messages are provided to all mothers. Active community-based counselling and support activities have been shown to significantly increase the practice of exclusive breast-feeding ${ }^{22}$, and need to be scaled up at programme level. Indeed, PMTCT services should be seen as an entry point for reinforcing messages of safer breastfeeding and implementing support activities for exclusive breast-feeding, regardless of the mother's HIV status ${ }^{23}$.

At the time of writing, the $\mathrm{MOH} / \mathrm{CW}$ of Zimbabwe was considering establishing two new time points for infant feeding counselling of all women: (1) at 10 days, provided in homes, to assist women in maintaining exclusive breastfeeding and (2) at 5 or 6 months, community-based, to support mothers during the introduction of complementary and/or replacement feeding, and to teach them the preparation of appropriate weaning food. These operational strategies may be particularly important for HIV-infected women in attempting to adopt current national and international guidelines for safe early cessation of breast-feeding and rapid weaning. The $\mathrm{MOH} / \mathrm{CW}$ was also evaluating the feasibility of training lay counsellors in infant feeding to increase community capacity to carry out such activities. Our study results support the need for such national initiatives for implementing strengthened infant feeding support services.

\section{Acknowledgements}

We would like to thank Mrs Rufaro Madzima, Head of Nutrition Unit at the $\mathrm{MOH} / \mathrm{CW}$, for reviewing the first draft of this manuscript; Dr Peter Iliff, Medical Director of the ZVITAMBO study, and Mr Renaud Becquet from ISPED for revising a later version. The contributions of the study team at Murambinda Mission Hospital, the Buhera District Medical Officer, the Manicaland Provincial Medical Directorate and Dr Agnes Mahomva from the national PMTCT unit are most appreciated. This study was conducted in the context of EGPAF funding (CTA grant \#26-01). The authors would like to acknowledge the continuing efforts of Dr Catherine Wilfert for encouraging and supporting the Murambinda PMTCT programme.

\section{References}

1 Cunningham AS, Jelliffe DB, Jelliffe EF. Breast-feeding and health in the 1980s: a global epidemiologic review. Journal of Pediatrics 1991; 118(5): 659-66.

2 De Cock KM, Fowler MG, Mercier E, de Vincenzi I, Saba J, Hoff E, et al. Prevention of mother-to-child HIV transmission in resource-poor countries: translating research into policy and practice. Journal of the American Medical Association 2000; 283(9): 1175-82.

3 Coutsoudis A, Pillay K, Spooner E, Kuhn L, Coovadia HM. Influence of infant-feeding patterns on early mother-to-child 
transmission of HIV-1 in Durban, South Africa: a prospective cohort study. South African Vitamin A Study Group. Lancet 1999; 354(9177): 471-6.

4 Iliff PJ, Piwoz EG, Tavengwa NV, Zunguza CD, Marinda ET, Nathoo KJ, et al. Early exclusive breastfeeding reduces the risk of postnatal HIV-1 transmission and increases HIV-free survival. AIDS 2005; 19(7): 699-708.

5 World Health Organization (WHO)/United Nations Children's Fund/United Nations Population Fund/Joint United Nations Programme on HIV/AIDS. HIV and Infant Feeding: Guidelines for Decision Makers. Geneva: WHO, 2003. Available at http://www.who.int/ child-adolescent-health/New_Publications/NUTRITION/ HIV_IF_DM.pdf. Accessed 26 August 2005.

6 World Health Organization (WHO). Global Strategy on Infant and Young Child Feeding. Geneva: WHO, 2003. Available at http://whqlibdoc.who.int/publications/2003/ 9241562218.pdf. Accessed 26 August 2005.

7 Rollins N, Meda N, Becquet R, Coutsoudis A, Humphrey J, Jeffrey B, et al. Preventing postnatal transmission of HIV-1 through breast-feeding: modifying infant feeding practices. Journal of Acquired Immune Deficiency Syndromes 2004; 35(2): 188-95.

8 Zimbabwe Ministry of Health and Child Welfare (MOH/CW)/Zimbabwe Centres for Disease Control/Joint United Nations Programme on HIV/AIDS. Zimbabwe National HIV and AIDS Estimates, 2003. Harare: $\mathrm{MOH} / \mathrm{CW}, 2003$.

9 Zimbabwe Ministry of Health and Child Welfare (MOH/CW). National HIV/AIDS Policy, Republic of Zimbabwe. Harare: $\mathrm{MOH} / \mathrm{CW}, 1999$.

10 Zimbabwe Ministry of Health and Child Welfare (MOH/CW), National Nutrition Unit. Infant Feeding and HIV/AIDS. Guidelines for Health Workers in Zimbabwe. Harare: $\mathrm{MOH} / \mathrm{CW}, 2000$.

11 Perez F, Orne-Gliemann J, Mukotekwa T, Miller A, Glenshaw M, Mahomva A, et al. Prevention of mother to child transmission of HIV: evaluation of a pilot programme in a district hospital in rural Zimbabwe. British Medical Journal 2004; 329(7475): 1147-50.

12 United Nations Children's Fund (UNICEF). Innocenti Declaration on the Protection, Promotion and Support of Breastfeeding. Florence, Italy: UNICEF, 1990. Available at http://www.unicef. org/programme/breastfeeding/innocenti.htm. Accessed 15 May 2005.

13 World Health Organization (WHO)/Joint United Nations Programme on HIV/AIDS (UNAIDS)/United Nations Children's Fund (UNICEF). HIV and Infant Feeding Counselling: A Training Course (Trainer's Guide). Report Nos. WHO/FCH/CAH/00.2-4, UNICEF/PD/NUT/(J)00-2 and UNAIDS/99.56E. Geneva: WHO/UNAIDS/UNICEF, 2000. Available at http://www.who.int/child-adolescenthealth/New_Publications/NUTRITION/HIV_Inf_Feeding/ Trainers\%20_Guide.pdf. Accessed 15 May 2005.

14 Central Statistical Office, Zimbabwe Ministry of Health and Child Welfare $(\mathrm{MOH} / \mathrm{CW}) / \mathrm{Macro}$ International. Zimbabwe Demographic and Health Survey. Harare: $\mathrm{MOH} / \mathrm{CW}$, 1999. Available at http://www.measuredhs.com/pubs/pdf toc.cfm?ID=296. Accessed 21 February 2005.

15 Origo D, Karemba M, Serima E. HIV affected couples in a support group addressing issues of alternative infant feeding without disclosing their HIV status. Paper presented at the XIVth International AIDS Conference, Barcelona, Spain, 712 July 2002; abstract no. WePeF6834.

16 Gaillard P, Piwoz E, Farley TM. Collection of standardized information on infant feeding in the context of mother-tochild transmission of HIV. Statistics in Medicine 2001; 20(23): 3525-37.

17 World Health Organization (WHO). Breastfeeding and Replacement Feeding Practices in the Context of Mother-ToChild Transmission of HIV - An Assessment Tool for Research. Report No. WHO/RHR/01.12. Geneva: WHO, 2001. Available at http://www.who.int/reproductive-health/rtis/docs/ Tool_breast_feeeding.doc. Accessed 15 February 2003.

18 Boerma JT, Gregson S, Nyamukapa C, Urassa M. Understanding the uneven spread of HIV within Africa comparative study of biologic, behavioral, and contextual factors in rural populations in Tanzania and Zimbabwe. Sexually Transmitted Diseases 2003; 30(10): 779-87.

19 Bland RM, Rollins NC, Solarsh G, VandenBroeck J, Coovadia HM. Maternal recall of exclusive breast feeding duration. Archives of Disease in Childhood 2003; 88(9): 778-83.

20 Kiarie JN, Richardson BA, Mbori-Ngacha D, Nduati RW, JohnStewart GC. Infant feeding practices of women in a perinatal HIV-1 prevention study in Nairobi, Kenya. Journal of Acquired Immune Deficiency Syndromes 2004; 35(1): 75-81.

21 Medley A, GarciaMoreno C, McGill S, Maman S. Rates, barriers and outcomes of HIV serostatus disclosure among women in developing countries: implications for prevention of mother-to-child transmission programmes. Bulletin of the World Health Organization 2004; 82(4): 299-307.

22 Piwoz EG, Iliff PJ, Tavengwa N, Gavin L, Marinda E, Lunney $\mathrm{K}$, et al. An education and counseling program for preventing breast-feeding-associated HIV transmission in Zimbabwe: design and impact on maternal knowledge and behavior. Journal of Nutrition 2005; 135(4): 950-5.

23 Humphrey J, Iliff P. Is breast not best? Feeding babies born to HIV-positive mothers: bringing balance to a complex issue. Nutrition Reviews 2001; 59(4): 119-27. 